\title{
Antibiotics in Medicine: friend or foe?
}

\author{
Kishan Sheth* \\ King's College London Dental School (BDS5), UK
}

He was once young, healthy and full of life. However now, Sean's pale, lifeless body lay still on the hospital bed, after they had fuelled his body with broad-spectrum antibiotics to manage the simple urine infection for which he had been rushed into A\&E. Medicine attempted to do its best despite lacking rapid diagnostic techniques to identify specific strains of bacteria, but the prescription of broad spectrum antibiotics presents a viscous cycle of more resistance, a cycle to which Sean fell victim. Later that week, his blood culture demonstrated gram-negative bacteria resistant to all antibiotics given to him when he was alive. These resistant strains were being encouraged to grow and reproduce by the decreasing levels of microbial competition. This ever-increasing risk is so grave that soon medicine as we know it, may become unable to control the problem it generates.

Since Penicillin's discovery by Sir Alexander Fleming, antibiotics have been considered the miraculous drug of the $20^{\text {th }}$ century [1]. It would be difficult to overstate how antibiotics have empowered doctors to save lives and revolutionised infection management. However, the loss of their effectiveness and reduction in their production by pharmaceutical companies has meant that medicine is now faced with a global crisis with people traveling internationally and carrying resistant strains with them. Surgeon General William Stewart claimed that the 'USA had wiped out infection', [2] little did he realise that the very use of antibiotics would create a very different type of problem. The high profile personalities of medicine attempted to raise alarm bells, and in 1945, Sir Alexander Fleming himself raised his personal concerns that the 'public will demand the drug and this will start an era of abuses', a hyperbole? Unfortunately, it was not. The medical profession kept on prescribing their newfound answer to all common illnesses [3].

According to the Centre for Disease Control and Prevention, in 2013, antibiotic resistant bacteria were responsible for 2 million cases of disease in the USA, of which over 23 thousand cases resulted in death. $50 \%$ of USA hospitalised patients receive antibiotic therapy, [4] and even when doctors are presented with non-bacterial causes of disease, they are still likely to prescribe antibiotics to rule out bacterial infections and protect themselves from future malpractice litigation, not to mention increasing pressures from patients for quick relief from symptoms, despite the likelihood of very little therapeutic value of the antibiotic drugs. The continuous misuse of antibiotics for minor infections has increased the risk potential. UK GPs prescribed 34 million antibiotics between 2015-2016 [5].

Is it too late to turn the tide on antibiotics leading the way to the end game of modern medicine? The increasing global usage of antibiotics and the growth in the numbers and populations of antibiotic resistant microorganisms has now become a serious, life threatening public health risk. The first case of Methicillin Resistant Staphylococus aureus was identified in the UK in 1962 [6]. Resistance in coagulasenegative staphylococci to Vancomycin was noted in 1979 [7]. There is evidence of increased resistance levels in Streptococcus pneumoniae and Streptococcus pyogenes, but more concerning are gram-negative strains such as proteobacteria, a warning that we may have a plethora of microorganisms emerging into this 'resistant' group very soon [8]. The chief medical officer for Britain has warned that 'antibiotic resistant bacteria with the potential to cause untreatable infections poses a catastrophic threat to the population' [9]. Furthermore, many high profile members of the medical community have begun raising their voices about the counterproductive ways in which modern medicine uses antibiotic therapy. Margaret Riley, Ph.D. Professor of Biology at the University of Massachusetts has stated that the usage of antibiotics for minor illnesses is like using 'a hydrogen bomb because it kills everything, all of your body's bacteria, the good and the bad'. In addition, in 2013 the Centre of Disease Control released a report, which pinpointed C. difficile as having earned a place in the 'top category of dangerous pathogens because of its widespread harm'. Michael Bell, stated that 'the type of C. diff circulating in the US today produces such a powerful toxin... that part of the colon needs to be surgically removed', highlighting the increasingly dangerous impacts of antibiotic resistant microorganisms on the body [10].

Masked bacterial infections are now believed to be the foundational cause of chronic fatigue syndrome, lupus, Parkinson's disease, and several cancers. Doctors generally prescribe a course of antibiotics for these diseases, which kill many probiotic species. Furthermore, many rheumatologists continue prescribing long courses of antibiotic for inflammatory arthritis, and cardiologists help manage cardiopathology via antibiotics in order to eradicate C. pneumoniae, a contributing factor in the formation and hardening of arterial plaque [11]. Infectious disease researcher, Curtis Donskey, believes 'too many physicians are still thinking of antibiotics as being benign... from an ecological point of view, we're starting to understand the medical consequences of disturbing ... (the normal micro flora) with antibiotics'. The disturbance of the normal micro flora makes a person a 'ticking time bomb' according to Salyers from the University of Illinois [12].

The pharmaceutical industry pumped very many novel antibiotics onto the market, however soon after; paused with their research for new antibiotics, and subsequently failed to keep up with the changing strands and mutations which the microorganisms underwent. They claimed there was simply 'no profit in it' [13]. Whilst it may be easy to point the finger at the industry, one cannot help but sympathise with them. As a business, without targeting significantly profitable sectors, they cannot afford to invest in new inventories, hire new talent or attract new investors. The pharmaceutical companies have been

Correspondence to: Kishan Sheth, King's College London Dental School (BDS5), UK, E-mail: kishan.sheth@kcl.ac.uk

Received: October 06, 2017; Accepted: October 23, 2017; Published: October 25,2017 
going after profits in chronic disease treatment modalities, such as diabetes, heart disease, obesity and cancer. Investing in low profit acute bacterial infection treatments is not seen to be as commercially viable because the financial and time costs are high, and antibiotics take up to '10 years to develop and can become useless in as little as a year' [13]. The developing time is so long due to the 4 stages of antibiotic testing before the drug can hit commercial markets. Despite all this, the Association of British Pharmaceutical Industry still continues to push for a more 'continual supply for effective antibiotics' which is unlikely to take place without government intervention, especially since more pharmaceutical companies are merging than ever before in this competitive business climate, resulting in shrinkages in the research teams as more staff are being laid off [13].

Despite the evidence for antibiotic resistance cases, doctors continue to oversubscribe worldwide. The IMS health Midas database that shows the volume of antibiotics sold (effectively equivalent to antibiotic usage and consumption), demonstrates that in 2010 there were 22 doses (a pill or ampoule) prescribed per person in the USA [14]. It is this trend of inappropriate prescribing which has led to the promotion of antibiotic resistant bacterial species. Less developed nations use tetracycline and streptomycin as rural pesticides, whilst more economically developed countries continue to use antibiotics as health and growth accelerators in livestock, which are later consumed by humans, and molecular detection techniques have demonstrated that antibiotic resistant bacterial species can potentially reach the bodies of their human consumers. Our challenge lies in incentivising farmers to not deliver antibiotics to their livestock or land, and also in being able to legally define what is 'inappropriate use' [15].

However, the daily practices that we have adopted and rejected have impacted on the exacerbation of antibacterial resistance. Herbal remedies, aloe vera and synergistic phytonutrients have been criticised by the media for being ineffective; probiotics, potentially accelerators of healthy microbial flora, are being ignored; [16] and poor hygiene and diet, particularly the inability of modern society to readily adopt the super-food revolution, has also accelerated the resistance issue. Pro-biotic species and a healthy balance of microbial flora can aid the process of digestion, rehydrate us and most importantly compete with the pathobionts to prevent disease occurrence. Regarding resistance mechanisms in gram-negative strains, we have lived with ESBL generating bacteria for 30 years and carriage rates in community and hospital A\&E are at $10 \%$. The evidence suggests the emerging problem is with carbapenems such as meropenem - our 'last resort antibiotic', and we are now experiencing many outbreaks at this current moment, including some London hospitals. This concern has led to many global leaders calling this a crisis.

'If we fail to act, we are looking at an almost unthinkable scenario where antibiotics no longer work and we are cast back into the dark ages of medicine', these words of David Cameron should raise alarm bells in all our minds [11]. There has been a huge amount of pressure from the media and medical profession to reduce the number of antibiotic prescriptions generated every year. It is hugely rewarding to see that Barack Obama has also successfully passed Generating Antibiotic Incentive Now in 2012, which extends patents of protected 'qualified infectious disease product' formularies by up to 5 additional years before generic competitors can saturate the market, increasing the rewards for drug companies who invest in successful antibiotics, and more commercial encouragement should be provided by governments to enable drug companies to become more competitive [17]. What should our battle plan entail? When we graduate from dental school, we have to make an oath to the public that we will knowingly commit no harm and protect their interests. Yet so few of us stop to challenge the status quo. We must stand up to the prescription generators and educate ourselves, our patients and our communities about this emerging problem. Together, we can empower a failed medical profession and build a bridge between patient and professional, one that supports a relationship of trust and ethical care, as well as better diagnostic tools to screen disease efficiently and effectively. We must also support and incentivise governments of less developed countries to invest in clean water supplies and better sanitation systems to reduce the risk of bacterial pathogenic transfer, thus reducing the need for antibiotics. There is no magic bullet to solving this global scenario, and in the same method that bacteria evolve in many different ways, medicine will need to evolve too in order to come up with strategies of discovering new antibiotics, monitoring their usage and encouraging patients and health professionals where possible, to use them as a last resort. Governments worldwide must reach out to each other and establish international guidelines for antibiotic usage in humans, animals and within the environment (particularly since in many South East Asian countries, all antibiotics are freely available on the high street - a practice which is illegal but still exists fuelling inappropriate usage); unite to develop more effective vaccines against many serious illnesses so that antibiotics can truly be a last resort; and conduct further research of bacteriophage viruses to explore its potential to attack certain strains of bacteria.

Might Pneumonia, Gonorrhea or Tuberculosis become incurable diseases? Although many healthcare professionals seem to still have their heads buried deep in the sand, more and more of us are awakening to the serious and potentially dark truth. We truly have reached a very critical and crucial point in medicine and our children and grandchildren may have to brunt the extremities of our poor decisions. Although as doctors and dentists we have a role to play in fulfilling our desire to do the best for the patient in our chair at the present moment, we must start to give more importance to the patients of tomorrow. We need to drive towards a more sustainable focus of medical practice and the truth is that we have no choice but to cut down on the consumption of antibiotics. However, if in this task we fail, we may find ourselves faced with a new strain of deadly bacteria, a new mass killer on the loose. One that is resistant to all known antibiotics. How then would the human race survive?

\section{References}

1. Alexander Fleming." Famous Scientists. 09 Jul. 2015. Web. ??8/24/2016 ?

2. Jones KE, Patel NG, Levy MA, Storeygard A, Balk D, et al. (2008) Global trends in emerging infectious diseases. Nature 451: 990-993. [Crossref]

3. Spellberg B, Gilbert DN (2014) The future of antibiotics and resistance: a tribute to a career of leadership by John Bartlett. Clin Infect Dis 59 Suppl 2: S71-75. [Crossref]

4. Jesse O'Shea. Antibiotic misuse and superbugs create the perfect killer, July 9, 2015

5. GPs praised for 'dramatic' cut in antibiotic prescriptions, 25 May 2016

6. Antibiotics in animal farming booklet, revised November 2011

7. Sengupta S, Chattopadhyay MK, Grossart HP (2013) The multifaceted roles of antibiotics and antibiotic resistance in nature. Front Microbiol 4: 47. [Crossref]

8. Centers for Disease Control and Prevention, Office of Infectious Disease Antibiotic resistance threats in the United States, 2013. Apr, 2013. Accessed January 28, 2015.

9. Ethan A. Huff, staff writer. Rise of antibiotic-resistant superbugs an 'apocalyptic threat' to humanity, say experts. Wednesday, February 06, 2013

10. Greg Pond. Antibiotics can not only make you sick, they can kill you. And a new report says they're doing so at a rate far greater than we realized. February 27, 2015. 
11. Review of antimicrobial resistance. May 2016.

12. Antibiotic resistance. Discover magazine.

13. Bax RP (1997) Antibiotic resistance: a view from the pharmaceutical industry. Clin Infect Dis 24 Suppl 1: S151-153. [Crossref]

14. Van Boeckel TP, Gandra S, Ashok A, Caudron Q, Grenfell BT, et al. (2014) Global antibiotic consumption 2000 to 2010: an analysis of national pharmaceutical sales data Lancet Infect Dis 14: 742-750. [Crossref]
15. Ventola CL (2015) The antibiotic resistance crisis: part 1: causes and threats. $P T 40$ : 277-283. [Crossref]

16. Beneficial Bacteria: Rejuvenate with Phytonutrients Encourage a healthy digestive tract and beneficial bacteria with prebiotic and probiotic supplements. The Herbs for Health Staff. May/June 1997

17. GAIN: How a New Law is stimulating the Development of Antibiotics. Antibiotic Resistance Project. November 07, 2013.

Copyright: $\odot 2017$ Sheth K. This is an open-access article distributed under the terms of the Creative Commons Attribution License, which permits unrestricted use, distribution, and reproduction in any medium, provided the original author and source are credited. 